\title{
Surgical Management of Primary Upper Limb Hyperhidrosis - A Review
}

\author{
Geesche Somuncuoğlu \\ Department of Thoracic Surgery, Schillerhoehe Hospital, Gerlingen, \\ Germany
}

\section{Introduction}

Sweating is a physiological and vital condition to control thermoregulation of the skin (Rajesh et al., 2003). Hyperhidrosis is defined as an excess of sweating beyond the amount needed to cool down elevated body temperature (Kreyden \& Burg, 2000).

Primary hyperhidrosis as a disease seems trivial to general public because of its falsely perceived rarity (Eisenach et al., 2005). Furthermore, although not life-threatening (Reisfeld et al., 2002), it is evident that it can lead to severe psychologic, social and occupational dysfunction (Shargall et al., 2008). Nowadays primary hyperhidrosis is being recognized increasingly and its treatment options are gaining widespread attention (Eisenach et al., 2005). Although medical therapies have been the main treatment options for many years, surgical interventions have recently been proven to be an important therapeutic alternative. This shift has corresponded with the evolution of minimally invasive surgical techniques (Grondin, 2008), the main topic of this issue.

\section{Classification and causes of hyperhidrosis}

Hyperhidrosis can be classified either by pathogenesis in a primary (idiopathic) and a secondary (symptomatic) form or by localisation and extension in a localised and a generalised form (Fig. 1).

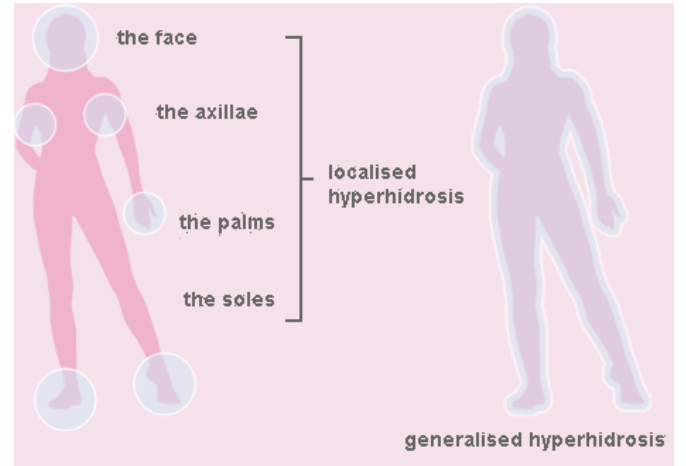

Fig. 1. Classification of hyperhidrosis by localisation and extension 
Secondary hyperhidrosis appears to be more generalised and is triggered by an underlying disease process like infectious, endocrine or neurologic disorders (Eisenach et al., 2005; Kreyden \& Burg, 2000; Shargall et al., 2008) (Table 1). Therapy of choice is treating the basic disease.

\begin{tabular}{|l|l|}
\hline Category & Disorders \\
\hline Infectious & Influenza, tuberculosis, \\
Endocrine & Hyperthyroidism, diabetes, menopause, obesity \\
Malignancy & Leukemia, lymphoma \\
Neurologic & Spinal cord injury, parkinson's disease \\
Drugs & Corticosteroids, antibiotics, antidepressants \\
Psychogenic & Panic disorder, stress, pain \\
\hline
\end{tabular}

Table 1. Causes of secondary hyperhidrosis

The cause of primary hyperhidrosis, mostly affecting local parts of the body, is still unknown (Duarte \& Kux, 2008). There seems to be a genetic predisposition in autosomal dominant fashion with variable penetrance, in $25-50 \%$ of cases a positive family history can be detected (Eisenach et al., 2005). The disease tends to begin in early childhood and becomes worse at puberty. It affects males and females equally (Shargall et al, 2008). The exact pathophysiology also remains unknown. There appears to be an overactive response of the eccrine glands to both heat and emotional stimuli, mediated through the sympathetic nervous system (Lee et al., 1999; Shargall et al., 2008) (Fig. 2). Therefore mostly affected areas are where eccrine glands are concentrated like the palms, the axillae, the face and the soles. Nearly half of diseased people suffer from an axillary manifestation (Schlereth et al., 2009). Overall the estimated prevalence of primary hyperhidrosis might be as high as $0,6-1 \%$ of the Western population, 2,8\% of the US population and even 3\% of the Asian population. Asia is also considered as an endemic area (Eisenach et al., 2005).

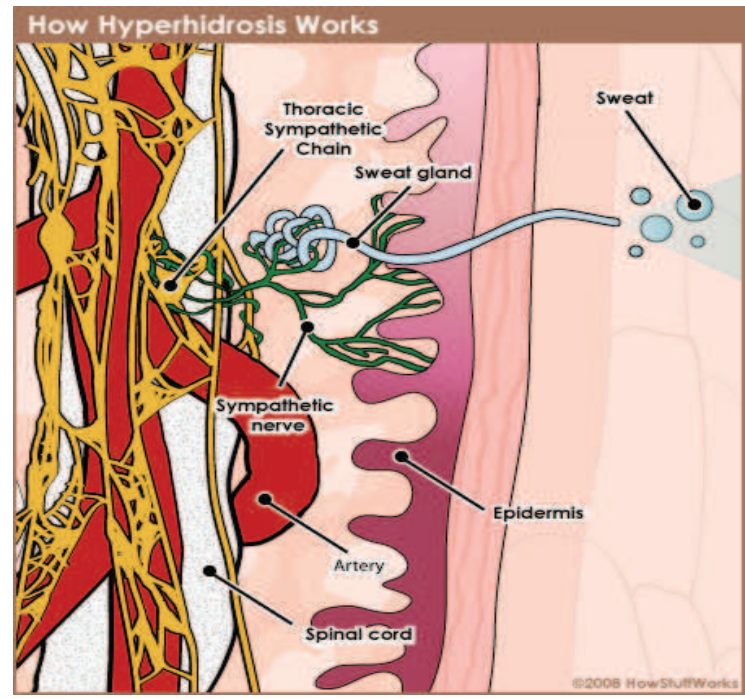

Fig. 2. Innervation of the eccrine glands by the sympathetic nervous system 


\section{Diagnosis and patient evaluation}

A substantial part of the diagnosis of hyperhidrosis can be achieved by obtaining a patients history, followed by a physical examination. Once secondary causes of hyperhidrosis have been ruled out by additional laboratory tests, dermatologists have several techniques to stratify the severity of sweating like gravimetric testing, the Minor starch-iodine test and the ninhydrin test. Quality-of-life assessments may support the categorization of primary hyperhidrosis as a serious medical condition (Eisenach et al., 2005; Solish et al., 2008).

\section{Treatment of primary hyperhidrosis}

Primary hyperhidrosis is treated symptomatically. There are lots of therapeutic options classified in nonsurgical and surgical treatment. Generally, therapy should be particular to each individual patient and chosen based on disease location, disease severity and expectations for improvement (Gee \& Yamauchi, 2008). Dermatologists suggest following a graduated scheme like the guidelines elaborated by the German Society of Dermatology (Wörle et al, 2007).

\subsection{Nonsurgical treatment}

The initial treatment for primary hyperhidrosis should always be nonsurgical. It includes topical treatments such as aluminium chloride, iontophoresis, oral medications such as anticholinergics and botulinum toxine (Reisfeld \& Berliner, 2008). Unfortunately, a lot of cases do not respond sufficiently to these treatment regimes and effects are usually transient (T.S. Lin, 2001). Nonsurgical therapy options are mostly practised by dermatologists, they are listed below (Table 2).

\begin{tabular}{|l|l|l|l|}
\hline $\begin{array}{l}\text { Therapy } \\
\text { option }\end{array}$ & Example & Indication & Mechanism/Specifics \\
\hline $\begin{array}{l}\text { Psycho- } \\
\text { vegetative } \\
\text { influence }\end{array}$ & $\begin{array}{l}\text { Autogenic training, hypnosis, } \\
\text { psychotherapy }\end{array}$ & $\begin{array}{l}\text { Generalised } \\
\text { adjuvant }\end{array}$ & $\begin{array}{l}\text { Psychovegetative damping } \\
\text { avoids activation of the reduced } \\
\text { threshold of the eccrine glands }\end{array}$ \\
\hline $\begin{array}{l}\text { Medications: } \\
\text { Topical }\end{array}$ & $\begin{array}{l}\text { Antiperspirants (aluminium } \\
\text { chloride hexahydrate) }\end{array}$ & Axillary & $\begin{array}{l}\text { Blocking the lumen of the eccrine } \\
\text { duct }\end{array}$ \\
- Systemic & $\begin{array}{l}\text { Anticholinergics, psychotropics, } \\
\text { betablockers }\end{array}$ & Generalised & $\begin{array}{l}\text { Anticholinergic, chemical } \\
\text { psychovegetative damping } \\
\text { Caution: Side effects }\end{array}$ \\
\hline $\begin{array}{l}\text { Physical } \\
\text { therapy }\end{array}$ & Iontophoresis & $\begin{array}{l}\text { Palmar } \\
\text { plantar }\end{array}$ & $\begin{array}{l}\text { Exact mechanism unknown: Ionic } \\
\text { current causes a temporary block } \\
\text { of the eccrine duct }\end{array}$ \\
\hline $\begin{array}{l}\text { Botulinum } \\
\text { toxin (BTX) }\end{array}$ & Local intradermal injection & $\begin{array}{l}\text { Axillary } \\
\text { palmar } \\
\text { plantar }\end{array}$ & $\begin{array}{l}\text { Chemical block: Inhibits the } \\
\text { release of acetylcholine at the } \\
\text { cholinergic synapse } \\
\text { Caution: Effect decreases within 6 } \\
\text { months }\end{array}$ \\
\hline
\end{tabular}

Table 2. Nonsurgical therapy options 


\subsection{Surgical treatment}

Surgery should be reserved to severe hyperhidrosis and should only be contemplated when less invasive nonsurgical options have failed to provide adequate treatment (Naunheim, 2000). It includes local surgical axillary procedures such as excision, curettage or liposuction of the sweat glands and thoracoscopic sympathectomy (Baumgartner, 2008) (Table 3).

\begin{tabular}{|l|l|l|l|}
\hline Therapy option & Procedure & Indication & Specifics \\
\hline $\begin{array}{l}\text { Excision of sweat } \\
\text { glands (En-bloc- } \\
\text { resection of dermis } \\
\text { and subcutis) }\end{array}$ & $\begin{array}{l}\text { Radical excision: several } \\
\text { techniques with plastic } \\
\text { skin suture }\end{array}$ & $\begin{array}{l}\text { Axillary } \\
\text { therapy-refractory }\end{array}$ & $\begin{array}{l}\text { Caution: Scarring, } \\
\text { contractures }\end{array}$ \\
\hline $\begin{array}{l}\text { Subcutaneous Excision } \\
\text { of sweat glands } \\
\text { (limited resection via } \\
\text { tiny incisions) }\end{array}$ & $\begin{array}{l}\text { - Curettage } \\
\text { - Liposuction }\end{array}$ & $\begin{array}{l}\text { Axillary } \\
\text { therapy-refractory }\end{array}$ & $\begin{array}{l}\text { Caution: Hematoma, } \\
\text { infection }\end{array}$ \\
\hline Sympathetic block & Thoracoscopic sympathectomy: Detailed description follows below \\
\hline
\end{tabular}

Table 3. Surgical therapy options

\subsubsection{Thoracoscopic sympathectomy}

The rationale for sympathectomy in the management of primary hyperhidrosis is based on interrupting the transmission of impulses from the sympathetic nervous system to the eccrine sweat glands (Reisfeld et al., 2002). Object of surgery is the sympathetic trunk, a series of ganglia which are located in a line lateral and parallel to the vertebral bodies of the spinal column. The thoracic portion of the sympathetic trunk contains 12 ganglia, where the input is switched over to the effector (Naunheim, 2000). Sweat glands are innervated segmentally, that means a certain ganglion level can be ascribed to a certain localisation of hyperhidrosis (C.C. Lin \& Telaranta, 2001). During the surgical procedure on the sympathetic trunk, the ganglia, lying in front of the heads of the ribs and covered by a thin layer of parietal pleura, are readily apparent with the lung retracted caudaly (Shargall et al., 2008) (Fig. 3).
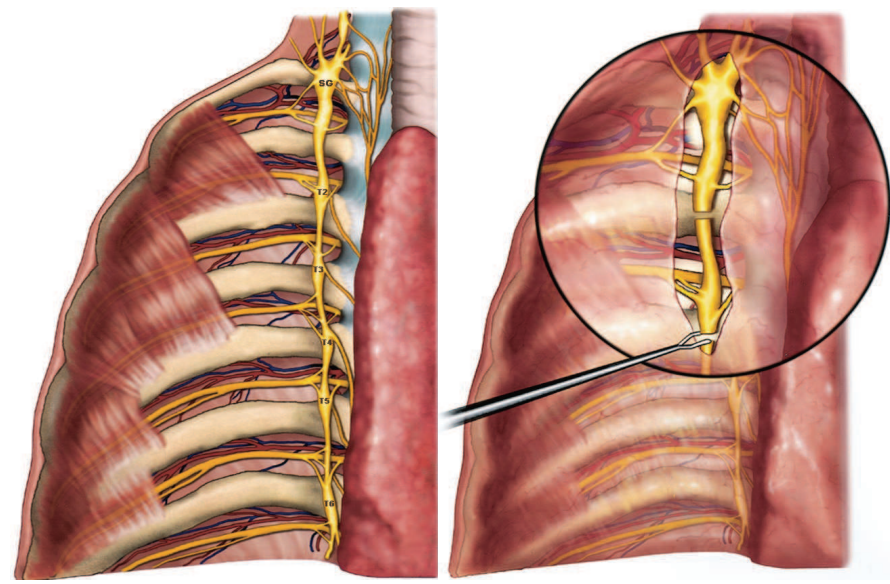

Fig. 3. Anatomy of the sympathetic trunk and applied surgical procedure 


\subsubsection{Surgical approaches and techniques}

The first open surgical approaches occurred nearly a century ago (Baumgartner, 2008). These aggressive approaches were associated with significant patient morbidity and a protracted recovery period (Dewey et al., 2006). They often required a moderate to large sized incision in the chest which demanded cutting muscles and separating ribs to expose the sympathetic chain (Naunheim, 2000). Over the past decade, endoscopic sympathectomy, requiring three or two small thoracal incisions, replaced open procedures (Fig. 4). Today magnification and high resolution, attained with videoassisted thoracoscopic surgery, allows a detailed representation of anatomical structures which reduces risk of complications (Zacherl et al., 1999) (Fig. 5). Meanwhile further advances, utilizing microinstrumentation called needlescopic surgery or using a uniportal access, enable procedures done on an outpatient basis with minimal risk of surgical trauma and excellent cosmetic results (Dewey et al., 2006; Lee et al., 2000).

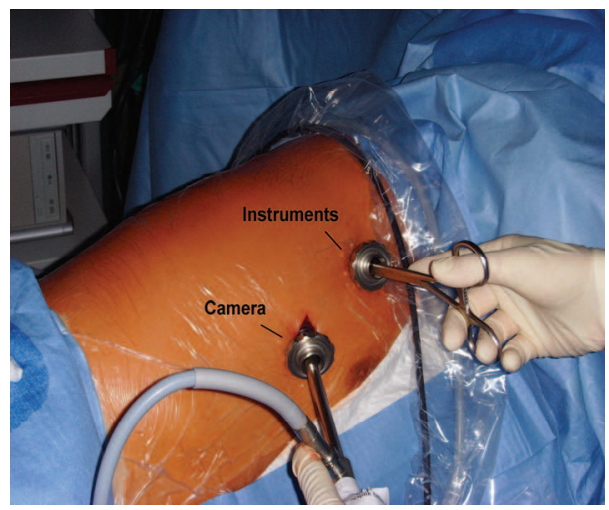

(a)

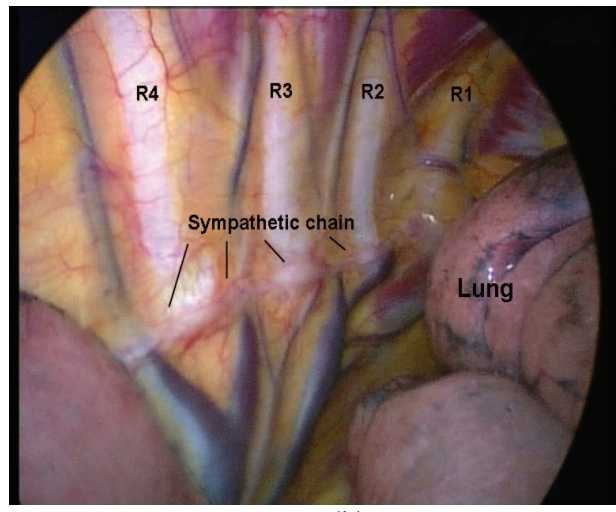

(b)

Fig. 4. (a) Example for a biportal access. (b) View via videothoracoscope ( $R=r i b)$

A short overview of the historical development of sympathetic surgery and its application as to primary hyperhidrosis is listed in the table below (Table 4).

\begin{tabular}{|l|l|}
\hline Year & History \\
\hline 1889,1896 & First open cervical sympathectomies for epilepsy by Alexander and Ionnesco \\
1920 & First open thoracal sympathectomies for hyperhidrosis by Kotzareff \\
1942 & First thoracoscopic sympathectomies for different pathologies by Hughes \\
1944 & Further thoracoscopic sympathectomies for different pathologies by Goetz and \\
1954 & $\begin{array}{l}\text { Marr } \\
\text { Further thoracoscopic sympathectomies for different pathologies by Kux and } \\
\text { Wittmoser } \\
1992\end{array}$ \\
1993 & $\begin{array}{l}\text { First videoassisted thoracoscopic surgery for posttraumatic pain syndrome by } \\
\text { Chandler } \\
\text { Further videoassisted thoracoscopic surgery for hyperhidrosis by Claes and } \\
\text { Drott presented at the First International Symposium on Thoracoscopic } \\
\text { Sympathectomy, Boras, Sweden }\end{array}$ \\
\hline
\end{tabular}

Table 4. Milestones in the history of sympathetic surgery and the therapy of hyperhidrosis 
Today much controversy and unanswered questions remain concerning the ideal thoracoscopic sympathetic operation (Baumgartner, 2008). What is the best technique of intervention: Should the sympathetic chain or ganglion be resected (sympathectomy), transected (sympathicotomy) or should only the rami communicantes be divided (selective sympathicotomy or ramicotomy)? Sympathectomy represents an aggressive approach, inducing a high rate of compensatory sweating (CS) (Lee et al., 1999). This unrequested side effect, specified below, could be considerably reduced by the nowadays commonly used sympathicotomy (Fig. 6). Another decrease of CS could be ascribed to ramicotomy, a limited technique first described by Wittmoser (Wittmoser, 1992) (Fig. 7). Due to the high rate of recurrence of preoperative symptoms, this approach is actually no longer used (Gossot et al., 2003).

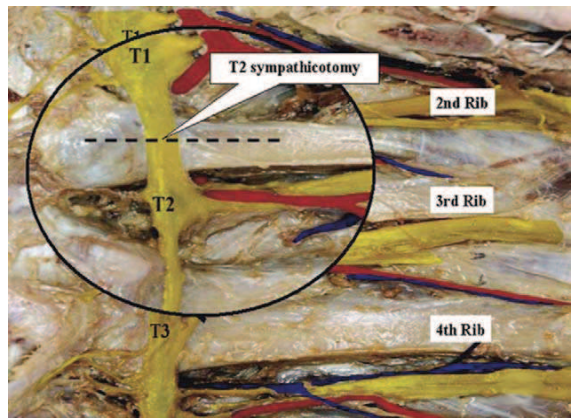

(a)

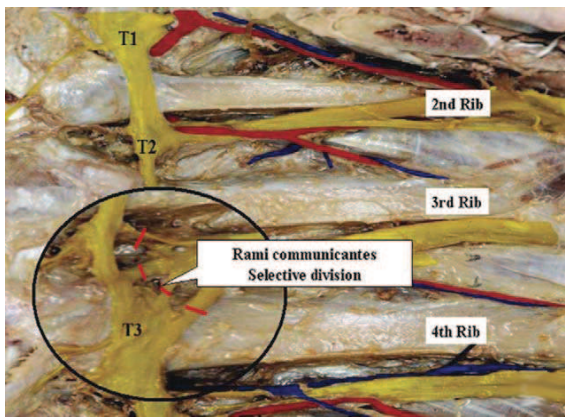

(b)

Fig. 5. (a) Sympathicotomy. (b) Ramicotomy

Which instrument should be utilised to dissect the sympathetic trunk: Harmonic scalpel, ultrasonic, laser or thermocoagulation? All of them yield similar results (Inan et al., 2008), but due to electrocautery, care should be exercised to avoid heat damage to the adjoining structures (Krasna, 2008). Another recently upcoming procedure is the clamping method, published by Lin and colleagues in 1998 (C.C. Lin et al., 1998) with the potential advantage of reversibility in those patients unhappy with the outcome (Reisfeld et al., 2002) (Fig. 6). But so far, there have been only a mere handful of such reversals done with the surgical clamping technique and these reported reversals met with varied success (Kwong et al., 2008). Neural cell death is supposed to be responsible, when the clips are not removed relatively soon postoperatively (Dewey et al., 2006).

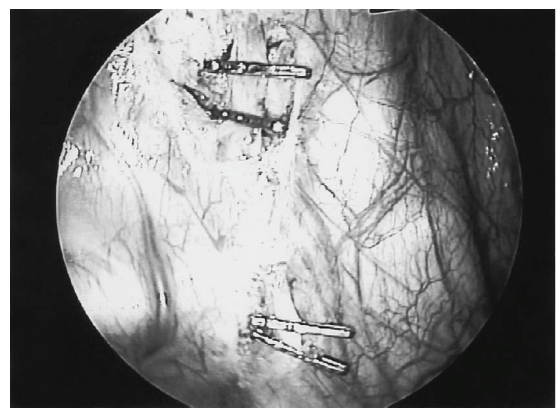

Fig. 6. Clamping method with two clips above and below the third rib 
At which level sympathectomy should be performed and what is the correct extent of the procedure? So far, there is no consensus among surgeons, but there seems to be a correlation to postoperative effect and occurrence of side effects. During a long period of time extensive resections from level T2 to T5 were commonly performed (Dewey et al., 2006; T.S. Lin \& Fang, 1999; Schmidt et al., 2006). But investigators demonstrated: reducing the extent of sympathectomy leads to a lower incidence of CS (Dumont, 2008). Today surgeons limit the extent of sympathectomy, there is a trend to two-level to the point of single-level surgery. The elected level of intervention is conditioned on the segmentally innervated localisation of hyperhidrosis and is shown in Table 5, based on a review of Krasna in 2008 (Krasna, 2008) (Table 5).

\begin{tabular}{|l|l|}
\hline Localisation & Level of intervention \\
\hline Facial & T2 \\
\hline Palmar & T2, T3 \\
\hline Axillary & T3, T4 \\
\hline Plantar & >T4 (obsolete) \\
& L2, L3 (today via endoscopic lumbar extraperitoneal sympathectomy) \\
\hline
\end{tabular}

Table 5. Localisation of primary hyperhidrosis and related level of intervention

T1 sympathectomy for facial hyperhidrosis is abandoned long time ago due to high risk of Horner's syndrome. For some time level of choice is T2 ganglia. Although T2 is also seen as centre point of neurologic impulse transmission through the brachial plexus to the hand (Hsia et al. 1999), some investigators suggest preparing lower levels like T3 (Dewey et al. 2006; Kwong et al., 2008; X. Li et al., 2008), because T2 is close to stellate ganglion with a risk of Horner's Syndrome non-negligible and the fact that higher levels can increase rate of CS (Schmidt et al., 2006). T4 still remains level of choice for axillary hyerphidrosis (Lee et al. 1999; Licht et al. 2005). Isolated plantar hyperhidrosis occurs rarely but rather in combination with palmar or axillary type. As combined manifestation it is often treated by sympathectomy for upper limb hyperhidrosis and leads in $85 \%$ of cases to an improvement of plantar symptoms, shown by Reisfeld and colleagues (Reisfeld et al., 2002). Causes of improvement are unknown. Treating plantar hyperhidrosis by preparing lower thoracic levels is no longer practised (Kwong et al., 2008). Today isolated plantar hyperhidrosis is treated at level L2 and L3 by endoscopic lumbar sympathectomy (Loureiro et al., 2008).

\subsubsection{Complications and side effects}

Complications in hyperhidrosis surgery are rare and exceptional. Some can be avoided by experience or by technical improvement of the surgeon, others are unforeseeable. However any complications are less acceptable than for other sorts of thoracic operations because sympathectomy is a functional surgery for young patients in good health (Dumont, 2008). In 2004 Ojimba and Cameron did a Medline search using the term thoracoscopic sympathectomy and analysed all publications for reported complications (Ojimba \& Cameron, 2004) (Table 6): No death has ever been reported in any published series but there are anecdotal reports of nine deaths following thoracoscopic sympathectomy. Five patients died from excessive haemorrhage, three due to incidents of narcosis and one death remained unexplained. Nevertheless, mortality associated with thoracoscopic sympathectomy is a rare condition compared to the high number of surgical procedures. The most common complication is pneumothorax. Up to $75 \%$ of patients have some residual 
gas or air in the thorax at the end of procedure, mostly resolving spontaneously. A temporary tube drainage is only required in $0,4-2,3 \%$ of cases, usually either after direct trauma to the lung at the time of trocar insertion, after dissolving adhesions or after rupture of a bulla as a consequence of anaesthesia, if high inflation pressures are used. Apart from the deaths mentioned above, reports of serious intraoperative bleeding are rare. Bleeding usually arises from disrupted intercostal veins or bleeding at the site of trocar insertion. The highest rate of significant bleeding with an incidence of 5,3\% was reported by Gossot and colleagues. They also described one laceration of the subclavian artery demanding an immediate thoracotomy (Gossot et al., 2001). Horner's Syndrome is the mostly feared complication. Occurred by irritation or damage to the stellate ganglion T1, it causes miosis, ptosis and enophthalmus on the same side of the face. Symptoms are often transient and decrease within weeks or months, but can also persist (Kaya et al., 2003). Since introduction of the videothoracoscope, which allows a better view, rate of postoperative Horner's Syndrome could be significantly reduced (Zacherl et al., 1999). However it is mentioned in almost all series. Gossot and colleagues found three main causes: damage by a direct or indirect current diffusion using diathermy, by excessive traction on the nerve during dissection or misdetermination of the ribs by the surgeon (Gossot et al., 2001). Pain in the form of intercostal neuralgia with dysesthesia at the site of trocar insertion is rarely documented but more frequent than generally recognized. Many centres perform short-stay surgery that may lead to underestimation of pain results. In most series pain resolves within months, but Walles and colleagues could detect a persistence for years (Walles et al., 2008). Further unfrequent complications are wound infection, pneumonia, chylothorax arising from laceration of an accessory thoracic duct (Gossot, 1996), rhinitis caused by increased parasympathetic stimulation of nasal mucosa (Herbst et al., 1994) and cardiopulmonary modification. The latter is recently paid particular attention: In a case report in 2009 $\mathrm{O}^{\prime}$ Connor and colleagues presented a patient with postoperative asystole. After successful resuscitation, permanent bradycardia required a pacemaker treatment ( $\mathrm{O}^{\prime}$ Connor et al., 2009). Surveys including pre-, peri- and postoperative measurements of cardiopulmonary function presented: the decreased activity of sympathetic nervous system after sympathectomy is comparable to the effect of a beta-blocker. It reduces heart rate and worsens pulmonary function. But the clinical importance of these findings was not significant (Vigil et al., 2005). However patients suffering from vasovagale syncope or high performance athletes should be advised of possible bradycardia and also asthmatics should be informed about potential deterioration of obstructive lung disease.

\begin{tabular}{|l|l|}
\hline More frequently reported complications & Less frequently reported complications \\
\hline Pneumothorax & Wound infection \\
Bleeding & Pneumonia \\
Horner's Syndrome & Chylothorax \\
Pain and Dysesthesia & Rhinitis \\
& Cardiopulmonary modification \\
\hline
\end{tabular}

Table 6. Overview of possible complications caused by thoracoscopic sympathectomy

Side effects are almost constant and unavoidable. They occur in nearly all series of surgery and therefore they are main topic of numerous articles (Dumont, 2008).

Compensatory sweating (CS) represents the most common side effect. It is defined as a postoperative increased sweating in body regions unaffected by sympathectomy (Lyra et al., 2008) (Fig. 7). The exact mechanism remains poorly understood. It is speculated that a 
greater amount of sweating elsewhere in the body compensates for the lack of sweating in the treated body area in order to maintain sweating balance of the whole body in a thermoregulatory way (Licht \& Pilegaard, 2004). In 2008 Lyra and colleagues tried to study the exact pathogenesis and assumed that sympathetic block causes a dysfunction of control loop with lack of negative feedback to the hypothalamus resulting in CS (Lyra et al., 2008).

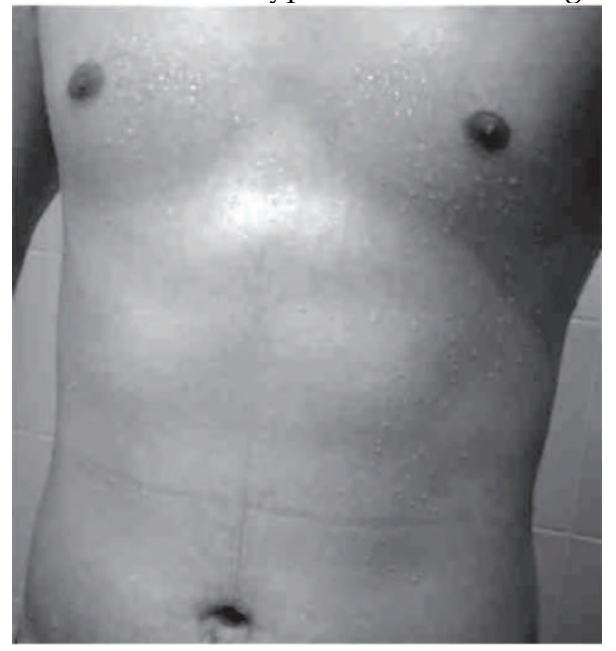

Fig. 7. Patient suffering from compensatory sweating of the thoracic and abdominal parts

The published rates of CS vary widely from 1,2-90\% (Dumont, 2008): On the one hand evaluating of CS is subjective and varies according to the patient (Leão et al. 2003). On the other hand most authors do not quantify a severity code. Some investigators only report on patients who have severe CS. They believe that almost all patients develop mild CS after sympathectomy (Ueyama et al., 2004). But also climate plays a decisive role (Lyra et al., 2008). High rates of CS are mostly found in studies of countries with warmer temperatures and humid weather (X. Li et al., 2008). Surgical technique also seems to influence the risk of CS: The lower the level of division and the smaller the extent of sympathectomy, the lower the incidence of CS (Dewey et al., 2006). Treatment options for severe CS are limited: Some investigators try local injection of botulinum toxine in areas where CS is the most severe (Bechara et al., 2006), others use the clamping method with moderate success. At the end of the nineties, Telaranta successfully performed reconstruction with nerve graft by open thoracotomy for a patient suffering from severe CS (Telaranta, 1998). But it is an individual case and a complex procedure. It should be able to avoid CS, because severity does not change over time in $70 \%$ of cases (Dumont, 2008). In Taiwan patients suffering from serious CS have already formed a support group based on an internet discussion forum to request the government to take this problem seriously (Hsu \& Y.C. Li, 2005). Therefore surgeons are searching for preoperative measurements to determinate postsympathectomy CS. In 2008 Miller and colleagues developed a new technique of a temporary thoracoscopic sympathetic block of the nerve with a local anesthetic that can hopefully predict severity of postoperative CS (Miller \& Force, 2008).

Gustatory sweating (GS) is defined as facial sweating when eating certain foods particularly spicy or acidic food (Licht \& Pilegaard, 2006) (Fig. 8). This phenomenon has no real 
explanation, the pathophysiology may be quite complex (Licht et al., 2005). GS is less commonly reported than CS. The reported incidence of GS varies considerably from $0-38 \%$ (Dumont, 2008). Except one study published by Licht and Pilegaard in 2006, which analyses the relation between extent of sympathectomy, primary localisation of hyperhidrosis and the incidence of GS (Licht \& Pilegaard, 2006), there are only a few investigators dealing with this issue. This occurrence is probably not estimated as very troublesome, both by surgeons and by patients. Furthermore triggers can be easily avoided by patients. Thus treatment options for GS including topical or systemic medications and the injection of botulinumtoxine are rarely performed (Eckardt \& Kuettner, 2003).

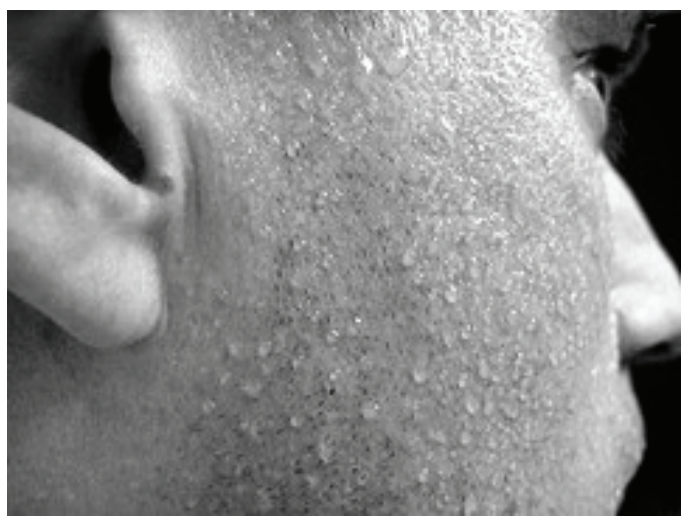

Fig. 8. Patient suffering from gustatory sweating

Due to unforeseeable and unacceptable complications and unavoidable side effects, careful patient selection is important for surgery. Patients should be fully informed before they decide on surgical treatment (Dumont, 2008).

\subsubsection{Postoperative results and patient satisfaction}

Literature suggests: Endoscopic thoracic sympathectomy is a safe and effective therapeutic strategy in patients suffering from severe primary hyperhidrosis with excellent results and high rates of patient satisfaction (Henteleff \& Kalavrouziotis, 2008).

Postoperative results seem to depend more on severity and primary localisation of hyperhidrosis than on surgical technique: Best results can be achieved in patients with severe palmar hyperhidrosis (Baumgartner \& Konecny, 2007). Patients with isolated axillary hyperhidrosis do not benefit sufficiently from sympathectomy (Gossot et al., 2003; Herbst et al., 1994). One possible explanation for the lower success rate may be that there is a combination of eccrine and apocrine sweat glands in the axilla. The eccrine sweat glands are innervated by sympathetic fibres, but the apocrine glands respond primarily to epinephrine. They are not blocked by sympathectomy and continue to function (Licht et al., 2005; Reisfeld et al., 2002). Therefore local surgical axillary procedures should be recommended as first-line therapy. As already mentioned, isolated plantar hyperhidrosis should be treated by endoscopic lumbar extraperitoneal sympathectomy. Individual reports with positive experiences already exist (Wörle et al., 2007). Also patients with facial hyperhidrosis or blushing do not universally and overwhelmingly benefit by sympathectomy., a case-by-case evaluation is required (Baumgartner, 2008). But patients with severe hyperhidrosis presenting 
for surgery mostly suffer from combined site hyperhidrosis (Eisenach et al., 2005). Reisfeld requests to establish indication for surgical therapy carefully: Thoracoscopic sympathectomy should only be performed in patients with severe palmar hyperhidrosis, other localisations should only be treated that way if combined with palmar site (Reisfeld et al., 2002).

Short-term studies on sympathectomy can be detected frequently, they continuously present great outcome depending on primary localisation. But unsatisfactory immediate results can occasionally be detected (de Campos et al., 2003). Causes for persistent postoperative sweating are inadequate knowledge and orientation of the surgeon or unrecognised variances of anatomic structures (D.H. Kim et al., 2005; Reisfeld et al., 2002; Yoon et al., 1999) including Kuntz nerve, a communicating sympathetic ramus crossing the second rib (Chung et al., 2002) (Fig. 9). Therefore some authors recommend extension of the sympathectomy line to about three or five centimetres lateral to the sympathetic chain by coagulating the surface of the corresponding rib, a method first described by Linder and colleagues in 1994 (Linder et al., 1994). Adequacy of sympathectomy is also tried to be detected by perioperative use of monitoring device like measuring skin surface temperature or plethysmographic blood flow (Lee et al., 1999; Yoon et al., 1999).

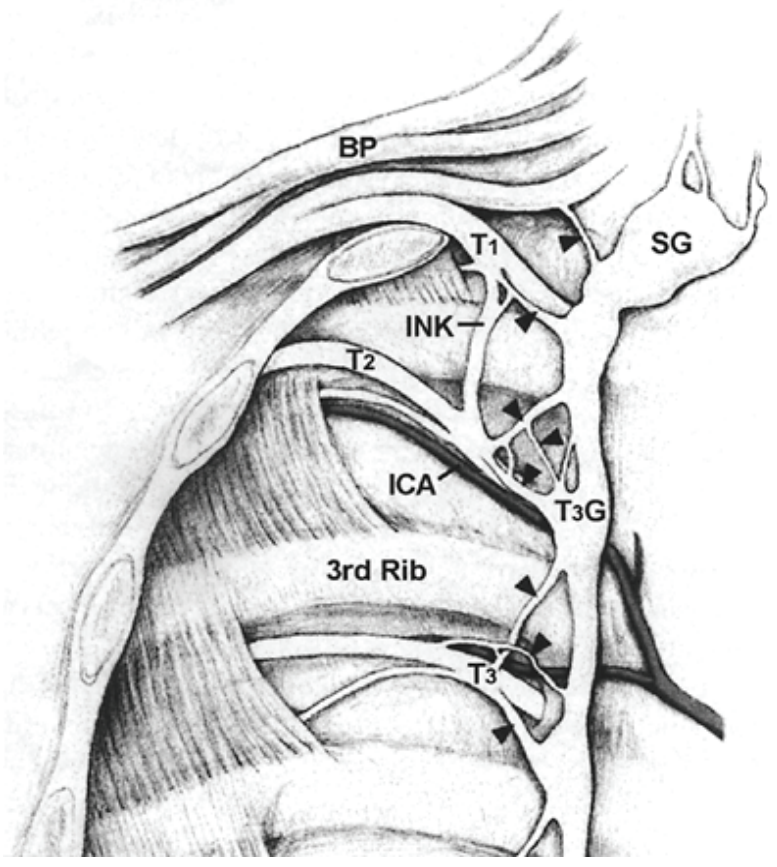

Fig. 9. Anatomy of Kuntz nerve (INK= intrathoracic nerve of Kuntz) and rami communicantes (arrowheads)

Long-term outcomes of more than 10 years are rarely reported (Zacherl et al., 1998). Investigations show that unfortunately results of sympathectomy deteriorate with time (T.S. Lin \& Fang, 1999; Walles et al., 2008). This recurrent postoperative sweating may be due to local nerve regeneration but has not yet been proven (Lee et al., 1999). 
Today some surgeons offer redo-operations in cause of persistent or recurrent postoperative sweating, also called re-sympathectomies. Usually these procedures can be reperformed by videothoracoscopy, severe pleural adhesions requiring thoracotomy are rarely documented (D.H. Kim et al., 2005; T.S. Lin, 2001). However there is a lack of long-term results too.

Lots of investigators use patient satisfaction as a common parameter to describe overall effectiveness of sympathectomy. Some studies reveal that patient dissatisfaction is primarily associated with persistence or recurrence of preoperative symptoms and to a lesser extent with incidence of side effects (Kwong et al., 2005; Walles et al., 2008). But assessment of surgical result using the conventional method patient satisfaction is imprecise and inaccurate (Leão et al. 2003). Main problem in requesting patient satisfaction, mostly based on patients self-report in questionnaires postoperatively, is subjectivity (Shargall et al., 2008). In some series several quality-of-life measures for assessment of improvements in daily life after treatment of hyperhidrosis are already used to get a more objective point of view (de Campos et al., 2003; Tetteh et al., 2009) (Table 7). In combination with quantitative measurements, which are often not practicable in the clinical setting, a precise evaluation of the effectiveness of sympathectomy would be possible (Cetindag et al., 2008).

\begin{tabular}{|l|l|}
\hline General tools & Specific hyperhidrosis tools \\
\hline - Illness Intrusive Rating Scale (IIRS) & - Hyperhidrosis Impact Questionnaire \\
- Medical Outcomes Trust Short Form & (HHIQ) \\
12 or 36 (SF-12 or SF-36) & - Hyperhidrosis Disease Severity Scale \\
- State-Trait Anxiety Inventory (STAI) & (HDSS) \\
- Symptom Distress Scale (SDS) & \\
- Dermatology Life Quality Index & \\
(DLQI) & \\
\hline
\end{tabular}

Table 7. Several tools used for Quality-of-life assessment

\section{Conclusion}

In literature database hundreds of citations can be identified concerning treatment of primary upper limb hyperhidrosis by thoracic sympathectomy and nearly all investigators suggest that patients can significantly benefit from this procedure.

But fundamental limitations arise: the great majority of currently available studies are retrospective single-centre series. The heterogeneity of study population, the inconsistent definition and terminology of the word sympathectomy, the variety of surgical techniques with the optimal procedure remaining elusive and the lack of uniform measures at both the exposure and outcome levels make comparison and generalisability of these series quite impossible. In future, in addition to standardization, both long-term studies with large numbers of patients and multicentre randomised controlled trials are mandatory to clearly define the role of sympathectomy in treatment of primary hyperhidrosis (Henteleff \& Kalavrouziotis, 2008).

\section{References}

Baumgartner, F. \& Konecny, J. (2007). Compensatory hyperhidrosis after sympathectomy: level of resection versus location of hyperhidrosis. The Annals of Thoracic Surgery, Vol.84, No.4, (October 2007), pp.1422 
Baumgartner, F.J. (2008). Surgical approaches and techniques in the management of severe hyperhidrosis. Review. Thoracic Surgery Clinics, Vol.18, No.2, (May 2008), pp. 167-81

Bechara, F.G.; Sand, M., Moussa, G., Sand, D., Altmeyer, P., Hoffmann, K. \& Schmidt, J. (2006). Treatment of unilateral compensatory sweating after endoscopical thoracic sympathectomy for general hyperhidrosis with botulinum toxin A. Dermatologic Surgery, Vol.32, No.5, (May 2006), pp. 745-48

Cetindag, I.B.; Boley, T.M., Webb, K.N. \& Hazelrigg, S.R. (2008). Long-term results and quality-of-life measures in the management of hyperhidrosis. Thoracic Surgery Clinics, Vol.18, No.2, (May 2008), pp. 217-22

Chung, I.H.; Oh, C.S., Koh, K.S., Kim, H.J., Paik, H.C. \& Lee, D.Y. (2002). Anatomic variations of the T2 nerve root (including the nerve of Kuntz) and their implications of sympathectomy. Journal of Thoracic and Cardiovascular Surgery, Vol.123, No.3, (March 2002), pp. 498-501

de Campos, J.R.; Kauffman, P., Werebe Ede, C., Andrade Filho, L.O., Kusniek, S., Wolosker, N. \& Jatene, F.B. (2003). Quality of life, before and after thoracic sympathectomy: report on 378 operated patients. The Annals of Thoracic Surgery, Vol.76, No.3, (September 2003), pp. 886-91

Dewey, T.M.; Herbert, M.A., Hill, S.L., Prince, S.L. \& Mack, M.J. (2006). One-year follow-up after thoracoscopic sympathectomy for hyperhidrosis: outcomes and consequences. The Annals of Thoracic Surgery, Vol.81, No.4, (April 2006), pp. 1227-32

Duarte, J.B. \& Kux, P. (1998). Improvements in video-endoscopic sympathicotomy for the treatment of palmar, axillary, facial, and palmar-plantar hyperhidrosis. European Journal of Surgery, Supplements 580, (1998), pp. 9-11

Dumont, P. (2008). Side effects and complications of surgery for hyperhidrosis. Review. Thoracic Surgery Clinics, Vol.18, No.2 (May 2008), pp. 193-207

Eckardt, A. \& Kuettner, C. (2003). Treatment of gustatory sweating (Frey's syndrome) with botulinum toxin A. Head \& Neck, Vol. 25, No.8, (August 2003), pp. 624-28

Eisenach, J.H.; Atkinson, J.L. \& Fealey, R.D. (2005). Hyperhidrosis: evolving therapies for a well-established phenomenon. Review. Mayo Clinical Proceedings, Vol. 80, No.5, (May 2005), pp. 657-66

Gee, S. \& Yamauchi, P.S. (2008). Nonsurgical management of hyperhidrosis. Thoracic Surgery Clinics, Vol.18, No.2 (May 2008), pp. 141-55

Gossot, D. (1996). Chylothorax after endoscopic thoracic sympathectomy. Case Report. Surgical Endoscopy, Vol.10, No.9 (September 1996), pp. 949

Gossot, D.; Kabiri, H., Caliandro, R., Debrosse, D., Girard, P. \& Grunenwald, D. (2001).Early complications of thoracic endoscopic sympathectomy: a prospective study of 940 procedures. The Annals of Thoracic Surgery, Vol.71, No.4, (April 2001), pp. 1116-19

Gossot, D.; Galetta, D., Pascal, A., Debrosse, D., Caliandro, R., Girard, P., Stern, J.B. \& Grunenwald, D. (2003). Long-term results of endoscopic thoracic sympathectomy for upper limb hyperhidrosis. The Annals of Thoracic Surgery, Vol.75, No.4, (April 2003), pp. 1075-79

Grondin, S.C. (2008). Hyperhidrosis. Preface. Thoracic Surgery Clinics, Vol.18, No.2, (May 2008), pp. ix-x 
Henteleff, H.J. \& Kalavrouziotis, D. (2008). Evidence-based review of the surgical management of hyperhidrosis. Thoracic Surgery Clinics, Vol.18, No.2, (May 2008), pp. 209-16

Herbst, F.; Plas, E.G., Függer, R. \& Fritsch, A. (1994). Endoscopic thoracic sympathectomy for primary hyperhidrosis of the upper limbs. A critical analysis and long-term results of 480 operations. Annals of Surgery, Vol.220, No.1, (July 1994), pp. 86-90

Hsu, M.H.; Li, Y.C. (2005). Compensatory sweating after thoracoscopic sympathectomy deserves more attention. The Annals of Thoracic Surgery, Vol.80, No.3, (September 2005), pp. 1160, author reply pp.1161

Inan, K.; Goksel, O.S., Uçak, A., Temizkan, V., Karaca, K., Ugur, M., Arslan, G., Us, M. \& Yilmaz, A.T. (2008). Thoracic endoscopic surgery for hyperhidrosis: comparison of different techniques. The Journal of Thoracic and Cardiovascular Surgery, Vol.56, No.4, (June 2008), pp. 210-13

Kaya, S.O.; Liman, S.T., Bir, L.S., Yuncu, G., Erbay, H.R. \& Unsal, S. (2003). Horner's syndrome as a complication in thoracic surgical practice. European Journal of CardioThoracic Surgery, Vol. 24, No.6, (December 2003), pp. 1025-28

Kim, D.H.; Paik, H.C. \& Lee, D.Y. (2005). Video assisted thoracoscopic re-sympathetic surgery in the treatment of re-sweating hyperhidrosis. European Journal of CardioThoracic Surgery, Vol. 27, No. 5, (May 2005), pp. 741-44

Krasna, M.J. (2008). Thoracoscopic sympathectomy: a standardized approach to therapy for hyperhidrosis. Review. The Annals of Thoracic Surgery, Vol.85, No.2, (February 2008), pp. 764-67

Kreyden, O.P. \& Burg, G. (2000). Die Giftbehandlung von Schweissperlen. Eine Übersicht der Hyperhidrose-Behandlung unter speziellem Blickwinkel der neuen Therapieoption mit Botulinumtoxin A. Schweizerische Medizinische Wochenschrift, Vol. 130, No. 29-30, (July 2000), pp. 1084-90

Kwong, K.F.; Hobbs, J.L., Cooper, L.B., Burrows, W., Gamliel, Z. \& Krasna, M.J. (2008). Stratified analysis of clinical outcomes in thoracoscopic sympathicotomy for hyperhidrosis. The Annals of Thoracic Surgery, Vol. 85, No.2, (February 2008), pp. 390-93, discussion pp. 393-94

Leão, L.E.; de Oliveira, R., Szulc, R., Mari, Jde. J., Crotti, P.L. \& Gonçalves, J.J. (2003). Role of video-assisted thoracoscopic sympathectomy in the treatment of primary hyperhidrosis. Sao Paulo Medical Journal, Vol.121, No.5, (September 2003), pp. 19197

Lee, D.Y.; Hong, Y.J. \& Shin, H.K. (1999). Thoracoscopic sympathetic surgery for hyperhidrosis. Yonsei Medical Journal , Vol. 40, No.6, (December 1999), pp. 589-95

Lee, D.Y.; Yoon, Y.H., Shin, H.K., Kim, H.K. \& Hong, Y.J. (2000). Needle thoracic sympathectomy for essential hyperhidrosis: intermediate-term follow-up. The Annals of Thoracic Surgery, Vol.69, No.1 (January 2000), pp. 251-53

Li, X.; Tu, Y.R., Lin, M., Lai, F.C., Chen, J.F. \& Dai, Z.J. (2008). Endoscopic thoracic sympathectomy for palmar hyperhidrosis: a randomized control trial comparing T3 and T2-4 ablation. The Annals of Thoracic Surgery, Vol. 85, No.5, (May 2008), pp. $1747-51$ 
Licht, P.B. \& Pilegaard, H.K. (2004). Severity of compensatory sweating after thoracoscopic sympathectomy. The Annals of Thoracic Surgery, Vol.78, No.2, (August 2004), pp. 427-31

Licht, P.B.; Jørgensen, O.D., Ladegaard, L. \& Pilegaard, H.K. (2005). Thoracoscopic sympathectomy for axillary hyperhidrosis: the influence of T4. The Annals of Thoracic Surgery, Vol.80, No.2 (August 2005), pp. 455-59, discussion pp. 459-60

Licht, P.B. \& Pilegaard, H.K. (2006). Gustatory side effects after thoracoscopic sympathectomy. The Annals of Thoracic Surgery, Vol.81, No.3, (March 2006), pp. 104347

Lin CC, Mo LR, Lee LS, Ng SM, Hwang MH (1998): Thoracoscopic T2-sympathetic block by clipping - a better and reversible operation for treatment of hyperhidrosis palmaris: experience with 326 cases. European Journal of Surgery, Supplements 580, (1998), pp. 13-16

Lin, T.S. \& Fang, H.Y. (1999). Transthoracic endoscopic sympathectomy in the treatment of palmar hyperhidrosis--with emphasis on perioperative management $(1,360$ case analyses). Surgical Neurology, Vol. 52, No. 5, (November 1999), pp. 453-57

Lin, T.S. (2001). Video-assisted thoracoscopic "resympathicotomy" for palmar hyperhidrosis: analysis of 42 cases. The Annals of Thoracic Surgery, Vol.72, No.3, (September 2001), pp. 895-98

Linder, A.; Friedel, G. \& Toomes, H. (1994). Thermometrically controlled thoracoscopic sympathectomy. Minimally Invasive Therapy, Vol.3, (1994), pp. 24

Loureiro, P.; de Campos, J.R., Kauffman, P., Jatene, F.B., Weigmann, S. \& Fontana, A. (2008). Endoscopic lumbar sympathectomy for women: effect on compensatory sweat. Clinics (Sao Paulo), Vol. 63, No.2, (April 2008), pp. 189-96

Lyra, M.; Campos, J.R., Kang, D.W., Loureiro, P., Furian, M.B., Costa, M.G. \& Coelho, S. (2008). Guidelines for the prevention, diagnosis and treatment of compensatory hyperhidrosis. Jornal Brasileiro de Pneumologia, Vol.34, No.11, (November 2008), pp. 967-77

Miller, D.L. \& Force, S.D. (2008). Temporary thoracoscopic sympathetic block for hyperhidrosis. The Annals of Thoracic Surgery, Vol. 85, No.4, (April 2008), pp. 12111214, discussion pp. 1215-16

Naunheim, K. (2000). Hyperhidrosis. Patient information. Epub. STS.org

O'Connor, K.; Molin, F., Poirier, P. \& Vaillancourt, R. (2009). Cardiac arrest as a major complication of bilateral cervico-dorsal sympathectomy. Interactive CardioVascular and Thoracic Surgery, Vol.8, No.2, (February 2009), pp. 238-39

Ojimba, T.A. \& Cameron, A.E. (2004). Drawbacks of endoscopic thoracic sympathectomy. Review. British Journal of Surgery, Vol. 91, No.3 (March 2004), pp. 264-69

Rajesh, Y.S.; Pratap, C.P. \& Woodyer, A.B. (2002). Thoracoscopic sympathectomy for palmar hyperhidrosis and Raynaud's phenomenon of the upper limb and excessive facial blushing: a five year experience. Postgraduate Medical Journal, Vol. 78, No.925, (November 2002), pp. 682-84

Reisfeld, R.; Nguyen, R. \& Pnini, A. (2002). Endoscopic thoracic sympathectomy for hyperhidrosis: experience with both cauterization and clamping methods. Surgical Laparoscopy Endoscopy \& Percutaneous Techniques, Vol.12, No.4, (August 2002), pp. 255-67 
Reisfeld, R. \& Berliner, K.I. (2008). Evidence-based review of the nonsurgical management of hyperhidrosis. Thoracic Surgery Clinics, Vol. 18, No.2, (May 2008), pp. 157-66

Schlereth, T.; Dieterich, M. \& Borklein, F. (2009). Hyperhidrose - Ursache und Therapie von übermäßigem Schwitzen. Deutsches Aerzteblatt International, Vol.106, No.3, (2009), pp. 32-37

Schmidt, J. \& Bechara, F.G., Altmeyer, P. \& Zirngibl, H. (2006). Endoscopic thoracic sympathectomy for severe hyperhidrosis: impact of restrictive denervation on compensatory sweating. The Annals of Thoracic Surgery, Vol.81, No.3, (March 2006), pp. 1048-55

Shargall, Y.; Spratt, E. \& Zeldin, R.A. (2008). Hyperhidrosis: what is it and why does it occur? Review. Thoracic Surgery Clinics, Vol.18, No.2, (May 2008), pp. 125-32

Solish, N.; Wang, R. \& Murray, C.A. (2008). Evaluating the patient presenting with hyperhidrosis. Thoracic Surgery Clinics, Vol.18, No.2, (May 2008), pp. 133-140

Telaranta, T. (1998). Secondary sympathetic chain reconstruction after endoscopic thoracic sympathicotomy. European Journal of Surgery, Supplements 580, (1998), pp. 17-18

Tetteh, H.A.; Groth, S.S., Kast, T., Whitson, B.A., Radosevich, D.M., Klopp, A.C., D'Cunha, J., Maddaus, M.A. \& Andrade, R.S. (2009). Primary palmoplantar hyperhidrosis and thoracoscopic sympathectomy: a new objective assessment method. The Annals of Thoracic Surgery, Vol.87, No.1, (January 2009), pp. 267-74, discussion pp. 274-75

Ueyama, T.; Ueyama, K., Ueyama, K. \& Matsumoto, Y. (2004). Thoracoscopic sympathetic surgery for hand sweating. Review. Annals of Thoracic and Cardiovascular Surgery, Vol.10, No.1, (February 2004), pp. 4-8

Vigil, L.; Calaf, N., Codina, E., Fibla, J.J., Gómez, G. \& Casan, P. (2005). Video-assisted sympathectomy for essential hyperhidrosis: effects on cardiopulmonary function. Chest, Vol. 128, No.4, (October 2005), pp. 2702-05

Walles, T.; Somuncuoglu, G., Steger, V., Veit, S. \& Friedel, G. (2008). Long-term efficiency of endoscopic thoracic sympathicotomy: survey 10 years after surgery. Interactive CardioVascular and Thoracic Surgery, Vol.8, No.1, (January 2009), pp. 54-57

Wittmoser, R. (1992). Thoracoscopic sympathectomy and vagotomy. In: Cuschieri, A., Buess, G., Perissat, J. Operative manual of endoscopic surgery. New York Springer Verlag, (1992), pp. 110-133

Wörle, B.; Rapprich, S. \& Heckmann, M. (2007). Definition und Therapie der primären Hyperhidrose. Journal der Deutschen Dermatologischen Gesellschaft, Vol.5, No.7, (June 2007), pp. 625-628

Yoon, Y.H.; Lee, D.Y., Kim, H.K. \& Cho, H.M. (1999). Reoperation for essential hyperhidrosis. Asian Cardiovascular E Thoracic Annals, Vol.7, No.1, (1999), pp. 5658

Zacherl, J.; Huber, E.R., Imhof, M., Plas, E.G., Herbst, F. \& Függer, R. (1998). Long-term results of 630 thoracoscopic sympathicotomies for primary hyperhidrosis: the Vienna experience. European Journal of Surgery, Supplements 580, (1998), pp. 4346

Zacherl, J.; Imhof, M., Huber, E.R., Plas, E.G., Herbst, F., Jakesz, R. \& Függer, R. (1999). Video assistance reduces complication rate of thoracoscopic sympathicotomy for hyperhidrosis. The Annals of Thoracic Surgery, Vol.68, No.4, (October 1999), pp. 117781 
TOpics w

THORACIC SURGERY

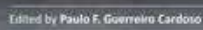

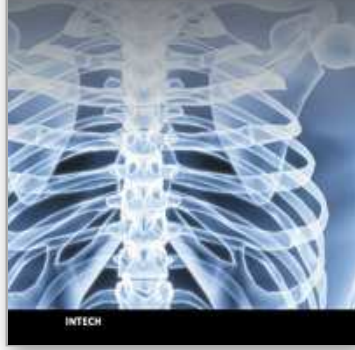

\section{Topics in Thoracic Surgery}

Edited by Prof. Paulo Cardoso

ISBN 978-953-51-0010-2

Hard cover, 486 pages

Publisher InTech

Published online 15, February, 2012

Published in print edition February, 2012

Thoracic Surgery congregates topics and articles from many renowned authors around the world covering several different topics. Unlike the usual textbooks, Thoracic Surgery is a conglomerate of different topics from Pre-operative Assessment, to Pulmonary Resection for Lung Cancer, chest wall procedures, lung cancer topics featuring aspects of VATS major pulmonary resections along with traditional topics such as Pancoast tumors and recurrence patterns of stage I lung disease, hyperhidrosis, bronchiectasis, lung transplantation and much more. This Open Access format is a novel method of sharing thoracic surgical information provided by authors worldwide and it is made accessible to everyone in an expedite way and with an excellent publishing quality.

\section{How to reference}

In order to correctly reference this scholarly work, feel free to copy and paste the following:

Geesche Somuncuoğlu (2012). Surgical Management of Primary Upper Limb Hyperhidrosis - A Review, Topics in Thoracic Surgery, Prof. Paulo Cardoso (Ed.), ISBN: 978-953-51-0010-2, InTech, Available from: http://www.intechopen.com/books/topics-in-thoracic-surgery/surgical-management-of-primary-upper-limbhyperhidrosis-a-review

\section{INTECH}

open science | open minds

\section{InTech Europe}

University Campus STeP Ri

Slavka Krautzeka 83/A

51000 Rijeka, Croatia

Phone: +385 (51) 770447

Fax: +385 (51) 686166

www.intechopen.com

\section{InTech China}

Unit 405, Office Block, Hotel Equatorial Shanghai

No.65, Yan An Road (West), Shanghai, 200040, China

中国上海市延安西路65号上海国际贵都大饭店办公楼 405 单元

Phone: +86-21-62489820

Fax: +86-21-62489821 
(C) 2012 The Author(s). Licensee IntechOpen. This is an open access article distributed under the terms of the Creative Commons Attribution 3.0 License, which permits unrestricted use, distribution, and reproduction in any medium, provided the original work is properly cited. 